\title{
Avaliação mecânica da placa de compósito de poli-hidroxibutirato e hidroxiapatita em modelos ósseos de gato
}

\author{
[Evaluation of the mechanics of of polyhydroxybutyrate and hydroxyapatite composite plates in \\ bone models of cat] \\ E.G.L. Alves, C.M.F. Rezende, H.P. Oliveira, N.F. Borges, P.F. Mantovani, J.S. Lara \\ Escola de Veterinária - UFMG \\ Av. Antônio Carlos, 6627 \\ 31270-901 - Belo Horizonte, MG
}

\begin{abstract}
RESUMO
Avaliou-se mecanicamente o compósito de poli-hidroxibutirato 70\% e hidroxiapatita 30\% na forma de placas para fixação óssea. Foram utilizadas 15 placas do compósito com $60 \mathrm{~mm}$ de comprimento por $10 \mathrm{~mm}$ de largura e espessura variando de $3 \mathrm{~mm}$ no centro a $5 \mathrm{~mm}$ nas extremidades, com seis orifícios. As placas foram fixadas em um modelo acrílico de fêmur de gato, e o conjunto foi submetido aos testes de flexão com quatro pontos, compressão axial e torção, empregando-se como referência microplacas de aço ASTM-F138 2,0mm. As médias das forças máximas nos testes de flexão e de compressão foram, respectivamente, de $323,20 \mathrm{~N}$ e $617,70 \mathrm{~N}$, para as placas de compósito, e de $352,33 \mathrm{~N}$ e $547,70 \mathrm{~N}$, para as placa de aço. No teste de torção, as médias dos torques máximos foram de 1,01Nm para as placas de compósito e de $1,15 \mathrm{Nm}$ para as placas de aço. Não houve diferença estatística entre as placas de compósito e de aço. O comportamento físico do material foi diferente, pois as placas de compósito se romperam e as de aço apenas se deformaram, revelando baixa ductilidade das placas de compósito.
\end{abstract}

Palavras-chave: gato, biomaterial, poli-hidroxibutirato, hidroxiapatita, osteossíntese

\begin{abstract}
Fixation bone plates made of $70 \%$ polyhydroxybutyrate and 30\% hydroxyapatite composite were mechanically evaluated. The fifteen composite plates employed presented six holes and measured $60 \mathrm{x}$ $10 \mathrm{~mm}$, length and width, respectively, with thickness ranging from 3 to $5 \mathrm{~mm}$ according to the region. The plates were fixed in acrylic models of cat femur, then were subjected to tests of four-points bending, axial compression, and torsion, using as reference $2 \mathrm{~mm}$ stainless steel plates. The means of the maximum force in flexion and compression tests were, respectively, 323.20N and 617,70N for the composite plates and $352.33 \mathrm{~N}$ and $547.70 \mathrm{~N}$ for the steel plates. In the torsional test, the means of torque were $1.01 \mathrm{Nm}$ for the composite plates and $1.15 \mathrm{Nm}$ for steel plates. There were no statistical differences between the plates of composite and steel. The physical behavior of the material was different once the composite plates broke up while the stainless steel ones only presented deformation, revealing the low ductility of the composite plates.
\end{abstract}

Keywords: cat, biomaterial, polyhydroxybutyrate, hydroxyapatite, osteosynthesis

\section{INTRODUÇÃo}

As ligas metálicas têm sido estudadas e utilizadas na fabricação de implantes ortopédicos há bastante tempo. São constituídas principalmente por ferro, cobalto, cromo, níquel e titânio, que conferem resistência e dureza necessárias aos implantes (Wang, 2003). No entanto, sequelas como corrosão, liberação de íons no organismo e osteoporose podem ser observadas após seu emprego (Uhthoff et al., 2006). Os íons da corrosão podem causar reações

Recebido em 30 de março de 2009

Aceito em 15 de outubro de 2010

E-mail: endrigogabellini@yahoo.com.br 
adversas como alergia, metalose e reação do tipo corpo estranho (Wang, 2003). Cistos periarticulares causados pela liberação de fragmentos metálicos (Niimi et al., 2007) e neoplasias associadas a implantes ósseos metálicos também têm sido relatados (McDonald et al., 2002).

As fixações com implantes metálicos são procedimentos bem-sucedidos (Uhthoff et al., 2006), contudo o osso cortical e o metal possuem propriedades mecânicas distintas. O módulo de elasticidade do osso cortical é de aproximadamente 20GPa, enquanto o de uma placa óssea de aço inoxidável é de cerca de 190GPa (Cordey et al., 2000). Essa diferença faz com que o implante absorva a maior parte das forças atuantes no osso, prevenindo o estresse mecânico sobre ele. A diminuição das forças sobre o osso pode levar ao seu enfraquecimento principalmente por osteoporose (Cordey et al., 2000; Uhthoff et al., 2006).

A força mecânica moderada, quando aplicada sobre o tecido ósseo, favorece a atividade osteoblástica e, com isso, a síntese de matriz óssea (Ocarino et al., 2007). A osteoporose devido à utilização de placas rígidas é causada pelo estresse de proteção. Macroscopicamente, observam-se o alargamento do canal medular e o adelgaçamento da cortical e, microscopicamente, verifica-se osteoporose cortical (Cordey et al., 2000). Além disso, a falha óssea decorrente da retirada dos parafusos atua como fator sinérgico predispondo à outra fratura após a retirada do implante (Uhthoff et al., 2006).

Face às complicações decorrentes da implantação de placas metálicas, dispositivos reabsorvíveis têm sido empregados em cirurgias ortopédicas sob a forma de placas, pinos e parafusos (Wang, 2003). Um dos benefícios dos implantes biodegradáveis utilizados em cirurgias ortopédicas é o de não serem removidos, evitando, portanto, um segundo procedimento cirúrgico, o que proporciona vantagens biológicas e econômicas (Saikku-Bäckström et al., 2005), principalmente no que se refere a animais cuja manipulação excessiva é indesejável, como alguns gatos, aves e animais silvestres. A manipulação desses animais geralmente acarreta estresse, interferindo na recuperação, e por isso, deve ser evitada.
Dentre os materiais utilizados na fabricação de implantes reabsorvíveis, destacam-se os biopolímeros e as biocerâmicas. Os compósitos constituídos por polímeros e cerâmicas bioativas são alternativas viáveis para a fabricação de implantes ósseos, pois possuem características físicas e químicas semelhantes ao osso (Boerre et al., 1993; Luklinska e Schluckwerder, 2003; Shishatskaya et al., 2006). Suas propriedades mecânicas podem ser modificadas para prover rigidez durante a regeneração óssea, degradandose numa velocidade que permita a transferência gradual da tensão do implante para o osso em consolidação, prevenindo, assim, o acúmulo de tensão no implante (Wang, 2003; SaikkuBäckström et al., 2005).

Muito se tem pesquisado na tentativa de reduzir o efeito da proteção ao estresse causado pela fixação óssea com placa rígida (Uhthoff et al., 2006), assim as placas com módulo de elasticidade semelhante ao do osso surgem como alternativa à fixação rígida, pois permitem melhor distribuição das forças entre osso e implante (Ganesh et al., 2005). As características físicas do compósito poli-hidroxibutirato e hidroxiapatita (PHB/HA) descritas na literatura, bem como a escassez de estudos de avaliação mecânica dos dispositivos de fixação fabricados a partir do compósito $\mathrm{PHB} / \mathrm{HA}$, estimularam a realização do presente trabalho, que teve o objetivo de avaliar o compósito polihidroxibutirato (PHB) 70\% e a hidroxiapatita (HA) $30 \%$ em gatos, com vistas a seu futuro emprego em animais de pequeno porte.

\section{MATERIAL E MÉTODOS}

As placas constituídas por compósito de polihidroxibutirato (Biocycle (PHB Industrial) Serrana, SP) $70 \%$ e hidroxiapatita (HAP-91 ${ }^{\circledR}$ (JHS Laboratório Químico S/A - Sabará, MG) 30\% foram confeccionadas no laboratório JHS (JHS Laboratório Químico S/A). Os implantes apresentavam forma retangular com $85 \mathrm{~mm}$ de comprimento por $10 \mathrm{~mm}$ de largura e espessura variando de $3 \mathrm{~mm}$ no centro da placa para $5 \mathrm{~mm}$ nas extremidades. Uma superfície era plana, e a outra côncava a qual foi justaposta ao modelo de fêmur. Todas as placas foram acondicionadas individualmente em embalagens comerciais (Embalagem para esterilização (Cipamed Embalagens Médico-Hospitalares - Ribeirão Preto, SP) e esterilizadas em óxido de etileno. 
Para o teste, as placas foram cortadas no tamanho de $60 \mathrm{~mm}$ de comprimento, e foram feitos seis orifícios equidistantes entre si. Para sua fixação foram utilizados parafusos (OrtovetOrtopedia Veterinária Comercial Ltda. - São Paulo, SP) de aço inoxidável ASTM-F138 de $2 \mathrm{~mm}$ de diâmetro, do tipo bicortical, com comprimento variável de acordo com a espessura do modelo.

Para melhor padronização dos testes mecânicos, foi necessária a confecção de modelos de fêmur em acrílico. Para a produção dos modelos, confeccionaram-se 24 moldes em gesso, que foram feitos a partir de um único fêmur de gato com $11,22 \mathrm{~cm}$ de comprimento, $1,00 \mathrm{~cm}$ de maior diâmetro da diáfise e $0,75 \mathrm{~cm}$ de menor diâmetro da diáfise. A produção do molde se deu em duas etapas. Iniciou-se com a confecção de meio molde, imergindo-se a metade caudal do fêmur de gato em uma densa massa de gesso localizada em uma caixa proporcional ao tamanho do fêmur. Após a secagem desta, foi aplicada uma camada de óleo mineral na superfície do molde para facilitar sua separação após a adição da segunda metade da massa de gesso. Após a secagem, as duas metades do gesso foram separadas e o osso foi cuidadosamente desprendido do molde e mantido à parte. Em seguida, foi feito um orifício, com cerca de $1 \mathrm{~cm}$ de diâmetro, na extremidade do molde correspondente à epífise distal do fêmur. Após a perfuração do molde, as duas metades foram unidas com fita adesiva e foi introduzida a resina acrílica, por gravidade, imediatamente após a mistura dos copolímeros pó (JET acrílico autopolimerizante, Artigos Odontológicos Clássicos Ltda., - São Paulo, SP) e líquido (JET acrílico autopolimerizante, Artigos Odontológicos Clássicos Ltda.) na proporção de $60 \%$ por $40 \%$, respectivamente. Após a secagem do acrílico, cerca de 10 minutos, o modelo acrílico foi retirado do molde e foram confeccionados os corpos de prova. Para isso, o modelo foi seccionado transversalmente no terço médio com serra manual (Arco de serra, Tramontina - Macaé, RJ) e fixado com placas de aço ou de compósito. As extremidades dos corpos de prova tiveram sua forma modificada nos testes de torção e compressão axial, para permitir o perfeito encaixe nas máquinas de teste.

Foram constituídos dois grupos, GA e GB. O grupo A foi constituído por nove corpos de prova formados pelos modelos seccionados e fixados por microplacas (Microplaca reta $2 \mathrm{~mm} 8$ furos, Hexagon Industria de Aparelhos Ortopédicos Ltda., Campinas, SP) de aço (ASTM-F138) 2,0, retas, com oito orifícios, com $60 \mathrm{~mm}$ de comprimento por $5 \mathrm{~mm}$ de largura e $1,2 \mathrm{~mm}$ de espessura. O grupo B foi constituído por 15 corpos de prova formados pelo modelo seccionado e fixados com placas de compósito de poli-hidroxibutirato (70\%) e hidroxiapatita (30\%), com seis orifícios de $3 \mathrm{~mm}$ de diâmetro, equidistantes entre si. O tamanho da placa foi reduzido para $60 \mathrm{~mm}$ de comprimento, mantendose a espessura e a largura originais. Todos os ensaios mecânicos foram realizados no laboratório de biomateriais do Departamento de Engenharia Metalúrgica e de Materiais da Escola de Engenharia da UFMG.

A metodologia utilizada para realização dos testes de flexão com quatro pontos e de torção foi adaptada de estudos semelhantes realizados por Sod et al. (2006). Para esses testes, os modelos de osso foram seccionados transversalmente em seu terço médio e fixados com as placas. Para o teste de flexão com quatro pontos, utilizou-se uma máquina universal de ensaios EMIC DL 3000 (EMIC Equipamentos e Sistemas de Ensaio Ltda. - São José dos Pinhais, PR), com célula de carga de $2000 \mathrm{~N}$ e velocidade de deslocamento de $10 \mathrm{~mm} / \mathrm{s}$. A base de apoio foi fixada a uma distância de $80 \mathrm{~mm}$. Os pontos de aplicação de força eram equidistantes à linha de secção e mantinham uma distância de $20 \mathrm{~mm}$ dela, totalizando $40 \mathrm{~mm}$ entre os pontos de aplicação de força. Foi considerada falha no teste de flexão com quatro pontos a ruptura dos corpos de prova ou a diminuição da força de resistência desses. Foi registrado o evento que aconteceu primeiro.

O equipamento usado no ensaio de torção consistiu de uma máquina hidráulica de torção (MST modelo 66.11A.02), uma unidade computadorizada MTS Teststar II $^{\mathrm{TM}}$ para controle hidráulico e a aquisição de dados. Foi utilizada uma célula de torque de $250 \mathrm{Nm}$ e uma taxa de deslocamento constante de $0,17 \mathrm{rad} / \mathrm{seg}$. $\mathrm{O}$ ensaio foi realizado até a ruptura do corpo de prova ou até o final do ciclo de uma volta completa. Foi considerada falha no teste de torção a ruptura dos corpos de prova ou a redução do torque desses. Foi registrado o evento que aconteceu primeiro. 
A metodologia utilizada para realização do teste de compressão axial foi adaptada de um estudo semelhante realizado por Esenkaya et al. (2007). Para esse teste, foi retirado um fragmento de $5 \mathrm{~mm}$ de extensão no terço médio do modelo em acrílico. A fixação da placa no modelo foi feita mantendo-se esta falha. Empregou-se para esse teste uma máquina universal de ensaios EMIC DL 3000 com duas bases de compressão. A célula de carga utilizada foi de $2000 \mathrm{~N}$, com velocidade de deslocamento de $10 \mathrm{~mm} / \mathrm{s}$. Foi considerada falha no teste de compressão axial a ruptura dos corpos de prova ou a diminuição da força de resistência desses, registrando-se o que acontecesse primeiro.

O delineamento utilizado foi o inteiramente ao acaso. Foram calculados as médias, as medianas, o desvio-padrão e o coeficiente de variação das forças e dos torques. As medianas das forças máximas e dos torques máximos obtidos nos testes mecânicos foram comparadas pelo teste de Mann-Whitney. Adotou-se um nível de confiança de $95 \%$.

\section{RESULTADOS E DISCUSSÃO}

O molde de gesso foi eficiente para a produção dos modelos de fêmur em acrílico. No entanto, alguns detalhes, como encontrar a densidade ideal da massa de gesso, foram importantes para se obter a apropriada imersão do exemplar de fêmur. $\mathrm{O}$ gesso de consistência muito mole permitia o afundamento completo do osso, e o de consistência muito firme impedia a confecção do molde na forma anatomicamente correta. A posição crâniocaudal do osso na massa de gesso permitiu sua retirada sem danificação do molde. Outras posições também foram tentadas, mas não foram eficientes, pois, ao se retirar o osso, sempre havia quebra de parte do molde.

A aplicação de uma camada de óleo mineral sobre a superfície da primeira metade do molde propiciou a separação das duas metades sem danos, após a secagem. A proporção da mistura dos copolímeros de $60 \%$ pó e $40 \%$ líquido, diferente do recomendado pelo fabricante, permitiu a produção de modelos sem bolhas e com polimerização em torno de 10 minutos. Foi necessária a produção de um molde de gesso para cada modelo, pois, após a polimerização, havia aderência do acrílico ao molde e, ao se desprender o modelo, sempre havia danificação do molde. Isso resultou na confecção de 24 modelos, os quais desempenharam bem seu papel na transmissão de forças para as placas de fixação. Quatro modelos (16,7\%) se romperam após a falha das placas de fixação, não interferindo, portanto, nas avaliações. Duas rupturas ocorreram no teste de compressão axial em modelos fixados com placas de compósito PHB/HÁ, e as outras duas no teste de torção em modelos fixados com placas de aço. Vários fatores afetam os resultados dos testes biomecânicos em ossos e devem ser considerados durante o procedimento. Os efeitos da variação entre os ossos quanto à idade, porosidade, tamanho, mineralização e geometria devem ser minimizados (Hammel et al., 2006; Sod et al., 2006). Para minimizar essa variação, utilizaram-se modelos ósseos iguais, feitos de metilmetacrilato, em todos os corpos de prova.

A escolha do metilmetacrilato como material para confecção dos modelos ocorreu em razão de suas propriedades mecânicas, módulo de elasticidade (2,9 GPa) e resistência mecânica (70 $\mathrm{MPa}$ ) (Oréfice, 2006), os quais apresentam valores próximos aos do osso cortical, que varia de 7 a $30 \mathrm{GPa}$ para o módulo de elasticidade, e de 50-150MPa para a resistência mecânica à flexão (Pereira et al., 2006). Na literatura consultada, não foram encontrados relatos sobre a resistência mecânica de implantes ortopédicos de compósitos PHB/HA. A placa metálica já é conhecida, padronizada e testada como meio eficiente de fixação de fraturas (Perren, 2002; Piermattei et al., 2006), motivo pelo qual foi utilizada como referência para avaliação mecânica das placas de PHB/HA.

Os testes biomecânicos são amplamente utilizados e aceitos para avaliar a eficiência de dispositivos de fixação ortopédica e devem ser realizados antes dos testes in vivo (Hammel et al., 2006; Sod et al., 2006). Os valores da força máxima suportada pelos corpos de prova e de deformação até a falha do implante estão mostrados na Tab. 1. A média da força máxima e a da deformação até a falha foram, respectivamente, de $352,33 \mathrm{~N}$ e $3,00 \mathrm{~mm}$ para os modelos fixados com placas de aço, e de 323,2N e 2,46mm para os fixados com placas de compósito PHB/HA. Os coeficientes de variação dos grupos aço (A) e compósito (B) apresentaram valores de $16,60 \%$ e $12,49 \%$, respectivamente, o que indica pequena variação 
nos resultados. Não houve diferença no comportamento das medianas para as amostras fixadas com a placa de aço e com a placa de compósito (Mann-Whitney, P-valor 0,3711), o que sugere força de flexão semelhante nas placas de aço e de compósito. Ossos submetidos a cargas excêntricas, como o fêmur e o úmero, suportam maior força de flexão (Hulsel e Hyman, 2003), o que torna o teste de flexão indispensável na avaliação mecânica de placas utilizadas para fixação desses ossos.

Os modelos fixados com as placas de aço apresentaram deformação elástica seguida de deformação plástica, ou seja, nos momentos iniciais do teste, a placa deforma-se, mas, quando a força é cessada, a placa volta a sua forma inicial. Do ponto de vista clínico, a deformação elástica é importante, uma vez que ela permite que o sistema volte à forma normal após a aplicação de força, desde que a força não supere o limite de deformação elástica. A deformação

elástica pode permitir a micromovimentação no foco de fratura, o que beneficia a consolidação óssea (Saikku-Bäckström et al., 2005; Uhthoff et al., 2006). No entanto, a amplitude de deformação elástica deve ser mínima, pois movimentos no foco de fratura podem levar à ruptura das aderências fibrinosas e fibrosas que se estabelecem entre as extremidades. Além disso, tais movimentos podem romper os vasos neoformados que atuam como ponte para as células osteoprogenitoras, retardando, assim, o processo de regeneração óssea (Perren, 2002; Uhthoff et al., 2006). A deformação elástica foi percebida ao final de cada teste de flexão, quando, ao se desligar a máquina de ensaio, o corpo de prova possuía uma angulação e, imediatamente após ser retirado da máquina de ensaios, essa angulação reduzia-se notavelmente. Nenhum corpo de prova fixado com a placa de aço apresentou ruptura, houve apenas a curvatura das placas (Fig. 1), que é considerada falha do implante.

\section{Grupo B}

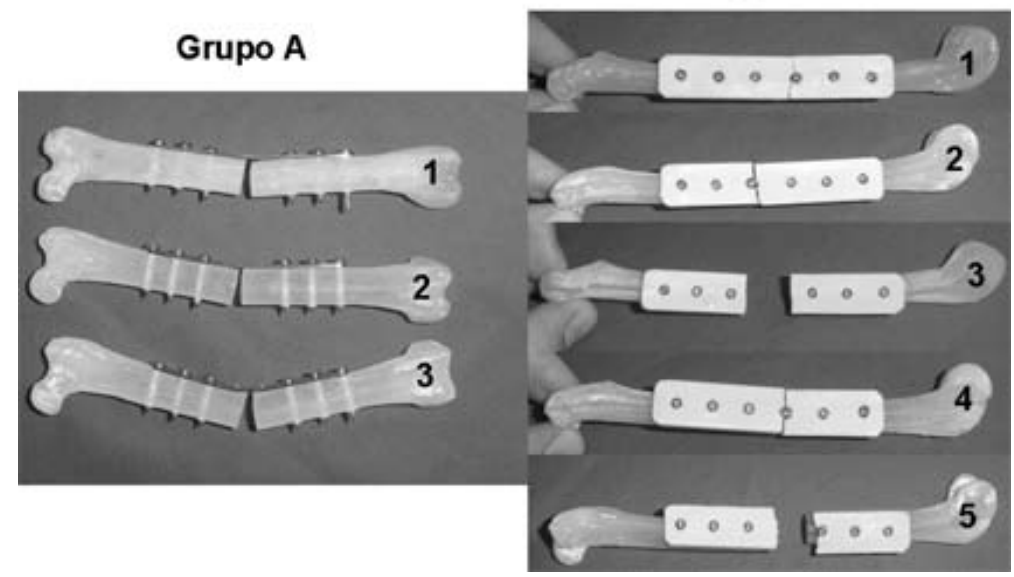

Figura 1. Corpos de prova fixados com placas de aço em modelos ósseos de gatos (Grupo A) e por placas de compósito PHB/HA (Grupo B) após a realização do ensaio de flexão com quatro pontos.

Os corpos de prova fixados com a placa de compósito apresentaram deformação média de 2,2mm e se romperam, perdendo completamente a função de estabilização. A quebra da placa originou uma linha de ruptura que se localizou, em $100 \%$ das amostras, na região adjacente à linha de secção do modelo. A localização da linha de ruptura nessa área já era esperada, uma vez que há concentração de tensão nesse local associada à fragilização da placa pelos orifícios de passagem dos parafusos (Ganesh et al., 2005; Hammel et al., 2006). Todas as linhas de ruptura das placas foram transversas ao eixo longitudinal, sendo que, na amostra três, localizou-se exatamente no ponto médio da placa; na amostra dois, sobre o orifício distal, no segmento proximal, adjacente à linha de secção, e nas amostras um, quatro e cinco, sobre o orifício proximal, no segmento distal, adjacente à linha de secção (Fig. 1). Em todos os casos, a ruptura ocorreu em uma área de sobrecarga da placa, ou seja, nos orifícios ou na linha de secção, ponto de maior concentração de tensão (Sod et al., 2006; Esenkaya et al., 2007). 


\section{Alves et al.}

Os valores do torque máximo suportado pelos corpos de prova e de deformação até a falha estão mostrados na Tab. 1. A média do torque máximo e da deformação até a falha foram de $1,50 \mathrm{Nm}$ e 0,83rad para os modelos fixados com placas de aço, e de $1,01 \mathrm{Nm}$ e $0,71 \mathrm{rad}$ para os modelos fixados com placas de compósito.

Tabela 1. Valores de força $(\mathrm{N})$ e torque $(\mathrm{Nm})$ máximos e deformação $(\mathrm{mm})$ até a falha dos modelos ósseos fixados com placas de aço e de compósito PHB/HA submetidos aos testes mecânicos de flexão com quatro pontos de apoio, torção e compressão axial

\begin{tabular}{|c|c|c|c|c|c|c|c|c|c|c|c|c|}
\hline \multirow{3}{*}{$\begin{array}{l}\text { Corpo } \\
\text { De } \\
\text { prova }\end{array}$} & \multicolumn{4}{|c|}{ Flexão com quatro pontos de apoio } & \multicolumn{4}{|c|}{ Torção } & \multicolumn{4}{|c|}{ Compressão axial } \\
\hline & \multicolumn{2}{|c|}{$\begin{array}{c}\text { Força máxima } \\
(\mathrm{N})\end{array}$} & \multicolumn{2}{|c|}{$\begin{array}{c}\text { Deformação } \\
\text { máxima (mm) }\end{array}$} & \multicolumn{2}{|c|}{$\begin{array}{c}\text { Torque máximo } \\
(\mathrm{Nm})\end{array}$} & \multicolumn{2}{|c|}{$\begin{array}{c}\text { Deformação } \\
\text { máxima (rad) }\end{array}$} & \multicolumn{2}{|c|}{$\begin{array}{c}\text { Força máxima } \\
(\mathrm{N})\end{array}$} & \multicolumn{2}{|c|}{$\begin{array}{l}\text { Deformação } \\
\text { máxima (mm) }\end{array}$} \\
\hline & Aço & $\begin{array}{l}\mathrm{PHB} / \\
\mathrm{HA}\end{array}$ & Aço & $\begin{array}{c}\mathrm{PHB} / \\
\mathrm{HA}\end{array}$ & Aço & $\begin{array}{c}\text { PHB/ } \\
\text { HA }\end{array}$ & Aço & $\begin{array}{c}\mathrm{PHB} / \\
\mathrm{HA}\end{array}$ & Aço & $\begin{array}{c}\text { PHB/ } \\
\text { HA }\end{array}$ & Aço & $\begin{array}{c}\text { PHB/ } \\
\text { HA } \\
\end{array}$ \\
\hline CP1 & 294,00 & 291,0 & 3,00 & 3,00 & 1 , & 2,24 & & 0,76 & & 739 & & 4,30 \\
\hline CP2 & 0 & 28 & 3,00 & 2,00 & 1,15 & 0,38 & 0,83 & 0,83 & 21 & 42 & 1,73 & 3,52 \\
\hline CP3 & 352,00 & 343,00 & 3,00 & 3,00 & 1,17 & 0,14 & 0,84 & 0,65 & 352,00 & 360,95 & 2,54 & 2,37 \\
\hline СР4 & - & 309,00 & - & 2,00 & - & 2,18 & - & 0,58 & - & 571,03 & 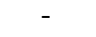 & 3,39 \\
\hline CP5 & - & 384,00 & - & 2,00 & - & 0,11 & - & 0,74 & 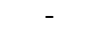 & 990,71 & - & 4,68 \\
\hline Média & 52,33 & 323,20 & 3,00 & 2,46 & 1,15 & 1,01 & 0,83 & 0,71 & 547,70 & 617,70 & 2,30 & 3,65 \\
\hline Mediana & 252,00 & 309,00 & 3,00 & 2,26 & 1,15 & 0,38 & 0,83 & 0,71 & 518,00 & 571,00 & 2,54 & 3,53 \\
\hline DP & 58,50 & 40,36 & 0,00 & 0,33 & 0,02 & 1,10 & 0,02 & 0,10 & 138,70 & 254,30 & 0,49 & 0,90 \\
\hline CV (\%) & 16,60 & 12,49 & 0,00 & 13,40 & 1,74 & 108,97 & 2,41 & 14,08 & 25,33 & 41,17 & 21,23 & 24,51 \\
\hline
\end{tabular}

$\mathrm{N}=$ newton; $\mathrm{mm}=$ milímetro; $\mathrm{Nm}=$ newton por metro; rad= radianos; $\mathrm{CP}=$ corpo de prova; $\mathrm{DP}=$ desvio-padrão; $\mathrm{CV}=$ coeficiente de variação.

Os coeficientes de variação dos grupos aço (A) e compósito (B) apresentaram os valores de 1,74\% e $108,97 \%$, respectivamente, o que indica pequena variação nos resultados apresentados pelo modelo fixado com placa de aço, mas grande variação nos resultados apresentados pelo modelo fixado com placa de compósito. Isso pode estar associado a problemas estruturais das placas de compósito. Não houve diferença no comportamento das medianas para as amostras fixadas com placa de aço e com placa de compósito (Mann-Whitney, $\mathrm{P}=0,7656$ ), o que sugere que a placa de compósito possui resistência à torção semelhante à placa de aço.

A neutralização da força de torção durante a fixação de uma fratura é importante, pois essa força gera o movimento mais deletério para a consolidação da fratura, que é a rotação entre os fragmentos ósseos (Hulse e Hyman, 2003; Piermattei et al., 2006). Essa rotação frequentemente causa a ruptura das aderências fibrosas e dos vasos neoformados nas extremidades ósseas fraturadas, retardando ou até mesmo impedindo o processo de reparação óssea (Piermattei et al., 2006)

Nenhuma placa de aço se rompeu no teste de torção, elas apenas se deformaram. Nos ensaios de torção das amostras um e dois, fixadas com as placas de aço, verificou-se ruptura do modelo acrílico na região distal desse, correspondente à metáfise óssea, a uma angulação de 1,87 e 4,17rad, respectivamente (Fig. 2). É importante salientar que a falha do modelo ocorreu a uma rotação muito superior a 0,84rad, considerado momento de falha das placas (Sod et al., 2006), ou seja, a ruptura do modelo não interferiu no estudo mecânico da placa. Os corpos de prova fixados com placa de compósito praticamente não apresentaram deformação.

Observou-se que, na rotação média de um ângulo de 0,71rad, as placas se romperam, originando múltiplos fragmentos com várias linhas de ruptura, mas, em todos os casos, verificou-se um componente oblíquo longo associado. A localização da ruptura foi adjacente à linha de secção do modelo, o que já era esperado, uma vez que há concentração de tensão nesse local, tornando-o mais susceptível (Ganesh et al., 2005; Hammel et al., 2006; Esenkaya et al., 2007).

As amostras um e quatro apresentaram linha de ruptura oblíqua longa simples passando em uma delas, pelo orifício distal do segmento proximal adjacente à linha de secção do modelo, e na outra, pelos dois orifícios adjacentes à linha de secção do modelo. Nas amostras três e cinco houve múltiplas linhas de ruptura, mas sempre com um componente oblíquo adjacente à linha de secção. A amostra dois exibiu uma fratura longitudinal passando pelos três orifícios no segmento proximal e tornando- se oblíqua na região adjacente a linha de secção (Fig. 2). No teste de torção, foi mais evidente a fragilização das placas pelos orifícios dos parafusos, uma vez que quase todas as linhas de ruptura (80\%) passaram por pelo menos dois orifícios. 


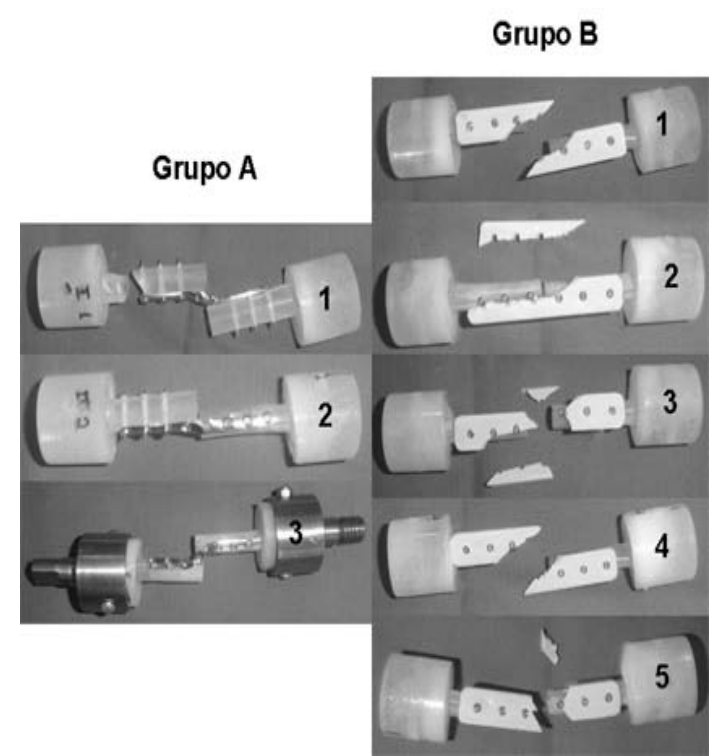

Figura 2. Corpos de prova fixados com placas de aço em modelos ósseos de gatos (Grupo A) e por placas de compósito PHB/HA (Grupo B) após a realização do ensaio de torção.

Nenhum corpo de prova fixado com a placa de aço apresentou ruptura e houve apenas a curvatura das placas (Fig. 3). A deformação elástica das placas de aço não foi percebida no teste de compressão, já a deformação plástica foi clara e se deu na região correspondente aos orifícios adjacentes ao defeito do modelo, ponto mais frágil e com maior concentração de tensão (Ganesh et al., 2005; Hammel et al., 2006). Os corpos de prova fixados com a placa de compósito mostraram deformação máxima média de $3,65 \mathrm{~mm}$ e se romperam, assim como nos outros testes mecânicos. A quebra da placa originou uma linha de ruptura transversa localizada na região adjacente ao defeito do modelo, em todas as amostras. A linha de ruptura da placa passou pelo orifício distal no segmento proximal adjacente ao defeito (Fig. 3).

\section{CONCLUSÕES}

A placa de compósito possui resistência máxima semelhante à da microplaca de aço 2.0. Os resultados encorajam a realização de outros estudos visando à aplicação prática da placa na fixação de fraturas. As placas de compósito apresentaram baixa ductilidade quando comparadas com as placas de aço.

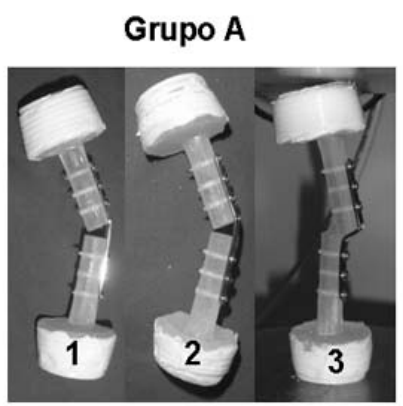

Grupo B

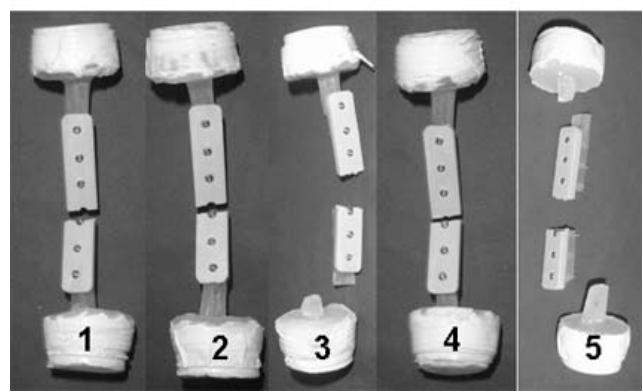

Figura 3. Corpos de prova fixados com placas de aço em modelos ósseos de gatos (Grupo A) e por placas de compósito PHB/HA (Grupo B) após a realização do ensaio de compressão axial.

\section{REFERÊNCIAS BIBLIOGRÁFICAS}

BOERRE, N.R.; DOVE, J.J.; COOPER, J. et al. Development of a degradable composite for orthopaedic use: Mechanical evaluation of an hydroxyapatite-polyhydroxybutirate composite material. Biomaterials, v.14, p.793-796, 1993.

CORDEY, J.; PERREN, S.M.; STEINEMANN, S.G. Stress protection due to plates: myth or reality? A parametric analysis made using the composite beam theory. Injury, v.31, supl.3, p.113, 2000.

ESENKAYA, I.; MISIRLIOGLU, M.; KELESTEMUR, M.H. et al. Biomechanical evaluation of different fixation plates in medial opening upper tibial osteotomy. Knee, v.14, p.46-50, 2007.

GANESH, V.K.; RAMAKRISHMA, K; GHISTA, D.N. Biomechanics of bone-fracture fixation by stiffness-graded plate in comparison with stainless-steel plates. Biomed. Eng. Online, v.2, p.1-15, 2005. 
HAMMEL, S.P.; PLUHAR, G.E.; NOVO, R.E. et al. Fatigue analysis of plates used for fractures stabilization in small dogs and cats. Vet. Sug., v.35, p.573-578, 2006.

HULSE, D.; HYMAN, D. Fracture biology and biomechanics. In: SLATTER, D. (Ed). Textbook of small animal surgery. 3.ed. Philadelphia: Saunders, 2003. v.1, p.1785-1792.

LUKLINSKA, Z.B.; SCHLUCKWERDER, H. In vivo response to HApolyhydroxybutyrate/polyhydroxyvalerate composite. J. Mycrosc., v.211, p.121-129, 2003.

MacDONALD, D.J.; ENNEKING, W.F.; SUNDARAM, M. Metal-associated angiosarcoma of bone: report of two cases and review of literature. Clin. Orthop. Relat. Res., v.396, p.206-214, 2002.

NIIMI, R.; HASEGAWA, M.; SUDO, A. et al. A large metallic cyst caused by wear particles alter total knee arthroplasty. Arch. Orthop. Trauma Surg., v.127, p.51-54, 2007.

OCARINO, N.M.; MARUBAYASHI, U.; CARDOSO, T.G. et al. Physical activity in osteopenia treatment improved the mass of bones directly and indirectly submitted to mechanical impact. J. Musculoskelet Neuronal Interac., v.7, p.84-93, 2007.

ORÉFICE, R.L. Materiais poliméricos - ciência e aplicações como biomateriais. In: ORÉFICE, R.L.; PEREIRA, M.M.; MANSUR, H.S. (Eds). Biomateriais fundamentos e aplicações. Rio de Janeiro: Cultura Médica, 2006. p.87-155.

PEREIRA, M.M.; VASCONCELOS, W.L.; ZAVAGLIA, C.A.C. Materiais cerâmicos ciência e aplicações como biomateriais. In: ORÉFICE, R.L.; PEREIRA, M.M.; MANSUR, H.S. (Ed). Biomateriais fundamentos $e$ aplicações. Rio de Janeiro: Cultura Médica, 2006. p.61-81.
PERREN, S.M. Evolution of the internal fixation of long bone fractures. J. Bone Joint Surg. Br., v.84, p.1093-1110, 2002.

PIERMATTEI, D.L.; FLO, G.L.; DECAMP, C.E. Handbook of small animal orthopedics and fracture repair. 4.ed. St. Louis: Saunders, 2006. 832p.

SAIKKU-BÄCKSTRÖM， A.; RÄIHÄ, J.E.; VÄLIMAA, T. et al. Repair of radial fractures in toy breed dogs with self-reinforced biodegradable bone plates, metal screws, and light-weight external coaptation. Vet. Sug., v.34, p.11-17, 2005.

SHISHATSKAYA, E.I.; KHULUSOV, I.A.; VOLOVA, T.G. A hybrid PHB-hydroyapatite composite for biomedical application: production, in vitro and in vivo investigation. $J$. Biomater. Sci. Polymer. Ed., v.17, p.481-498, 2006.

SOD, G.A.; HUBERT, J.D.; MARTIN, G.S. et al. An in vitro biomechanical comparison between prototype tapered shaft cortical bone screw and AO cortical bone screws for an equine metacarpal dynamic compression plate fixation of osteotomized equine third metacarpal bones. Vet. Surg., v.35, p.634-642, 2006.

UHTHOFF, H.K.; POITRAS, P.; BACKMAN, D.S. Internal fixation of fractures: short history and recent developments. J. Orthop. Sci., v.11, p.118-126, 2006.

WANG, M. Developing bioactive composite materials for tissue replacement. Biomaterials, v.24, p.2133-2151, 2003. 